\title{
Contrasting Responses of Arbuscular Mycorrhizal Fungal Families to Simulated Climate Warming and Drying in A Semiarid Shrubland
}

Maria Mar ALGUACIL ( $\square$ mmalguacil@cebas.csic.es )

CEBAS-CSIC https://orcid.org/0000-0001-8495-8707

Klaus Schlaeppi

Institute for Sustainability Sciences

Álvaro López-García

CEBAS-CSIC

Marcel van der Heijden

Institute for Sustainability Sciences

José Ignacio Querejeta

CEBAS-CSIC

\section{Research Article}

Keywords: Arbuscular mycorrhizal fungi, diversity, SMRT sequencing, drought stress, warming, drylands

Posted Date: June 24th, 2021

DOl: https://doi.org/10.21203/rs.3.rs-632259/v1

License: (9) This work is licensed under a Creative Commons Attribution 4.0 International License.

Read Full License 
Contrasting responses of arbuscular mycorrhizal fungal families to simulated climate warming and drying in a semiarid shrubland

María del Mar Alguacil ${ }^{1 *}$, Klaus Schlaeppi ${ }^{2,5,6,7}$, Álvaro López-García ${ }^{1}$, Marcel G.A. van der Heijden ${ }^{2,4,5}$, José Ignacio Querejeta ${ }^{3}$

${ }^{1}$ Soil Microbiology and Symbiotic Systems Department, Estación Experimental del Zaidín, CSIC, Profesor Albareda 1, Granada 18008, Spain.

${ }^{2}$ Plant-Soil-Interactions, Institute for Sustainability Sciences, Agroscope, Reckenholzstrasse 191, 8046 Zürich, Switzerland.

${ }^{3}$ CSIC-Centro de Edafología y Biología Aplicada del Segura. Department of Soil and Water Conservation. P.O. Box 164, Campus de Espinardo 30100-Murcia (Spain).

${ }^{4}$ Plant-Microbe-Interactions, Department of Biology, Utrecht University, 3508TB Utrecht, the Netherlands.

${ }^{5}$ Department of Evolutionary Biology and Environmental Studies, University of Zurich, Winterthurerstrasse 190, 8057 Zürich, Switzerland.

${ }^{6}$ Institute of Plant Sciences, University of Bern, Switzerland

${ }^{7}$ Department of Environmental Sciences, University of Basel, Switzerland

Author for correspondence: mar.alguacil@eez.csic.es 


\section{Abstract}

We carried out a 4-year manipulative field experiment in a semiarid shrubland in Southeastern Spain to assess the impacts of experimental warming (W), rainfall reduction $(\mathrm{RR})$ and their combination $(\mathrm{W}+\mathrm{RR})$ on the composition and diversity of arbuscular mycorrhizal fungal (AMF) communities in rhizosphere soil using singlemolecule real-time (SMRT) DNA sequencing. Across climate treatments, we encountered 109 AMF OTUs that were assigned to four families: Glomeraceae (93.94\%), Gigasporaceae (2.19\%), Claroideoglomeraceae (1.95\%) and Diversisporaceae (1.92\%). The AMF community composition and diversity indices at OTU level were unaffected by the climate manipulation treatments, except for a significant decrease in AMF richness in the $\mathrm{W}$ treatment relative to the control. In contrast, AMF family richness decreased significantly in all the climate manipulation treatments relative to the control treatment. Members of the Gigasporaceae and Diversisporaceae families appeared to be highly vulnerable to intensification of heat and drought stress, as their abundances decreased by $67 \%$ and $77 \%$ respectively, in the $\mathrm{W}+\mathrm{RR}$ treatment relative to current ambient conditions. In contrast, the relative abundance and dominance of the Glomeraceae family within the AMF community increased significantly under the W+RR treatment, with Glomeraceae being indicator family for the $\mathrm{W}+\mathrm{RR}$ treatment. The interaction between warming and rainfall reduction had a significant effect on AMF community structure at family level. These findings provide new insights into AM fungal community responses to climate warming and drying in dryland ecosystems.

\section{Keywords}

Arbuscular mycorrhizal fungi, diversity, SMRT sequencing, drought stress, warming, drylands 
Arbuscular mycorrhizal (AM) fungi are important symbiotic partners of the majority of terrestrial plant species and depend on the photosynthetic carbon provided by the host plant for their growth and function [1]. In return, AM fungi (AMF) can enhance host-plant nutrient and water uptake and resistance to environmental stresses such as drought. It has been shown that coexisting AM fungi show host plant preferences [2], are functionally distinct [3] and that AM community diversity can affect plant community diversity and productivity and, therefore, ecosystem stability and sustainability [4].

It is accepted that AM associations are differently influenced by environmental variation across ecosystem types, showing no general patterns in the majority of environmental manipulation experiments conducted until now in natural conditions [5]. The semiarid Mediterranean ecosystems in Southeast Spain are frequently exposed to severe drought episodes and heatwaves, erosive processes during heavy rainstorms and vegetation cover losses. These processes lead to degraded habitats which are among the most fragile and endangered by environmental changes such as global warming [6]. The key role of AMF in improving the physiological functioning and performance of dryland plant communities and soil quality is well established [7-10]. However, the extent to which ongoing climatic changes could affect the composition and structure of AMF communities in dryland ecosystems is still unknown, since most research has focused on plant community responses to climate change drivers [11, 12]. Investigating the response of AMF communities to simulated climate warming and drying and identifying the major factors driving AMF community assembly in soils is necessary to help the management and conservation of the biodiversity and functions of semiarid ecosystems.

We carried out a 4-year manipulative field experiment in a semiarid shrubland in Southeastern Spain (Sorbas, Almería). We simulated future warmer and drier climate conditions, in order to investigate the effect of increased temperature (W), rainfall reduction $(\mathrm{RR})$ and their combination $(\mathrm{W}+\mathrm{RR})$ on AMF community composition and species richness. Details on the experimental design and treatment impacts on climatic conditions within the experimental plots are provided in the supplementary information section (S1), [12, 13].

We collected 45 rhizosphere soil samples across the four climate treatments (Control, W, RR, W+RR), extracted genomic DNA from 300-mg of each individual rhizosphere soil sample and quantified the AMF communities by single-molecule real time (SMRT) 
DNA sequencing. We followed the molecular and bioinformatic protocol described in Schlaeppi et al. [14]. We sequenced 3 SMRT®Cells at the Functional Genomic Centre Zurich (Zurich, Switzerland; http:// www.fgcz.ch). Operational Taxonomic Units (OTUs) were clustered at a level of $97 \%$ sequence similarity and classified by AMF family using specific AMF taxonomy [15].

To ascertain whether the AMF community structure was affected by the climate manipulation treatments, we conducted a permutational multivariate analysis of variance (perMANOVA) (adonis function, vegan R package, [16] using Bray-Curtis as measure of dissimilarity and 999 permutations. A non-metric multidimensional scaling (NMDS) ordination using Bray-Curtis as dissimilarity measurement was performed to visualize differences in AMF community structure among treatments (metaMDS function, vegan package in $\mathrm{R}$ ).

Alpha diversity indices (richness -S- and Shannon-Weaver index - $\mathrm{H}^{\prime}-$ ) were calculated for the AMF community at both OTU and family levels (specnumber and diversity functions, vegan $\mathrm{R}$ package). The influence of the climate manipulation treatments on $\mathrm{H}^{\prime}$ and $\mathrm{S}$ was determined by a two-way ANOVA analysis and a post-hoc Tukey-HSD test.

An indicator species analysis (ISA) was conducted using the family abundance data (indicspecies R package, [17]. All statistical analyses were performed in R (v4.0.4; [18]).

In total, 67,222 reads were obtained from 45 samples which were assigned to 278 OTUs. From them, 115 OTUs were assigned to the phylum Glomeromycota. After singletons and non-assigned sequences were removed, 109 AMF OTUs (26,768 sequences) were assigned to four families: Glomeraceae (93.94\%), Gigasporaceae (2.19\%), Claroideoglomeraceae (1.95\%) and Diversisporaceae (1.92\%).

The climate manipulation treatments had no significant effects on AMF community structure or diversity indices at OTU level (every term in perMANOVA: pseudo $F_{1,44}<1.2, \mathrm{p}>0.1, \mathrm{R}^{2} \leq 0.02$ ) (Table $\mathrm{S} 1$, Fig. $\mathrm{S} 1$ ), except for a significant decrease in AMF richness in the $\mathrm{W}$ treatment relative to the control. However, the AMF family richness decreased significantly and consistently in all the climate manipulation treatments relative to the control treatment (W, RR and W+RR; F:3.42, p<0.026) (Table 1). The relative abundance and dominance of the Glomeraceae family within the AMF community increased significantly under the W+RR treatment (Fig. 1), with Glomeraceae being indicator family for the $\mathrm{W}+\mathrm{RR}$ treatment (IndVal=0.61; $\mathrm{p}<0.05$ ). 
Moreover, the interaction between warming and rainfall reduction had a significant effect on AMF community structure at family level (perMANOVA: pseudo $F_{1,44}=4.7$, $\mathrm{p}=0.005, \mathrm{R}^{2}=0.09$ ) (Table $\mathrm{S} 1$ ). The Shannon diversity index did not show significant differences between treatments for OTUs or families.

Previous studies have shown that increased heat and drought stress strongly reduced photosynthetic rates, aboveground plant growth and drought survival in this semiarid shrubland community by $\sim 20-40 \%$ [12], especially in the $\mathrm{W}+\mathrm{RR}$ treatment, which likely reduced carbon supply to AMF $[19,20]$. Decreased AMF family richness in the simulated climate change treatments could thus be consequence of shifts in belowground carbon flow pathways, as plants could increasingly favor their more beneficial AMF partners through preferential carbon allocation to them at the expense of less beneficial AMF under warmer and drier conditions [21]. Alternatively, decreased AMF family richness under a warmer and drier climate could be the result of increased competition among AMF taxa for a dwindling carbon supply by host roots, with some high carbon demanding AMF being outcompeted by less carbon demanding AMF or more aggressive AMF competitors for root space and/or carbon supply.

Among the four AMF families detected in our study, Gigasporaceae and Diversisporaceae were the most sensitive to the intensification of heat and drought stress, as their abundances in the $\mathrm{W}+\mathrm{RR}$ treatment decreased by $67 \%$ and $77 \%$ respectively, relative to current ambient conditions (Fig.2). By contrast, Glomeraceae and Claroideoglomeraceae showed the highest abundances under the most stressful climate conditions (W+RR) with an average $20 \%$ increase over the control. Moreover, Glomeraceae was by far the most abundant AMF family in our dryland ecosystem across climate treatments and was also the unique indicator family for the W+RR treatment. These patterns may reflect functional differences among AMF taxa that have been proposed to rely on different life-history strategies [22]. Taxa within the Glomeraceae and Claroideoglomeraceae families tend to allocate more biomass to intraradical structures than to external hyphae, whereas those in the Gigaporaceae and Diversisporaceae display the opposite tendency [3]. Treseder et al. [23] suggested that when carbon allocation to AMF decreases as consequence of global change stressors, members of the Gigasporaceae tend to show decreasing abundance linked to their higher carbon demand to support the growth and maintenance of their profuse external hyphal network. In contrast, the Glomeraceae strategy is based on extensive root colonization and randomly connected hyphae with limited production of extraradical mycelium, 
which has been interpreted as an adaptive strategy to avoid and resist drought conditions in soil $[3,24]$.

In conclusion, this study provides new insights and improves our understanding of AM fungal community responses to climate warming and drying under the global climate change scenarios predicted for Mediterranean drylands during the second half of the XXIst century.

\section{Author's Contribution}

JIQ designed the study; JIQ and MMA collected the samples; MMA, KS, MVH, ALG analyzed and interpreted the data; MMA, JIQ wrote the manuscript, with substantial input from all co-authors.

\section{Funding}

This study was funded by the Spanish Ministerio de Economía y Competitividad (project CGL2013-48753-R co-funded by European Union FEDER funds). MMA acknowledges a mobility stay of researchers in foreign centers ("Jose Castillejo") from Spanish Ministerio de Economía y Competitividad.

\section{Data Availability}

The raw sequencing data is available from the European Nucleotide Archive (http://www.ebi.ac.uk/ena) with the sample ID SAMEA4711908 under the study accession PRJEB21595.

\section{Compliance with Ethical Standards}

\section{Conflict of Interest}

The authors declare that they have no conflict of interest.

\section{Ethics}

Approval Not applicable

\section{References}


1. Smith SE, Read DJ (2008) Mycorrhizal symbiosis, 3rd edn. Academic Press, Cambridge

2. Torrecillas E, Alguacil MM, Roldán A (2012) Host preferences of arbuscular mycorrhizal fungi colonizing annual herbaceous plant species in semiarid mediterranean prairies. Appl Environ Microbiol 78:6180-6.

3. Chagnon PL, Bradley RL, Maherali H, Klironomos JN (2013) A trait-based framework to understand life history of mycorrhizal fungi. Trends Plant Sci 18:484-491

4. Van der Heijden MGA, Klironomos JN, Ursic M, Moutoglis P, Streitwolf-Engel R, Boller T, Wiemken A, Sanders IR (1998) Mycorrhizal fungal diversity deter-mines plant biodiversity, ecosystem variability and productivity. Nature 396:69-72.

5. Cotton TEA (2018) Arbuscular mycorrhizal fungal communities and global change: an uncertain future. FEMS Microbiol Ecol 94:11.

6. Fu Q, Feng S (2014) Responses of terrestrial aridity to global warming. J Geophys Res Atmos 119:7863-7875.

7. Alguacil MM, Caravaca F, Roldan A (2005) Changes in rhizosphere microbial activity mediated by native or allochtonous AM fungi in the reafforestation of a Mediterranean degraded environment. Biol Fertil Soils 41:59-68

8. Querejeta JI, Allen MF, Caravaca F, Roldán A (2006) Differential modulation of host plant $\delta^{13} \mathrm{C}$ and $\delta^{18} \mathrm{O}$ by native and nonnative arbuscular mycorrhizal fungi in a semiarid environment. New Phytol 169:379-387

9. Querejeta JI, Allen MF, Alguacil MM, Roldán A (2007) Plant isotopic composition provides insight into mechanisms underlying growth stimulation by AM fungi in a semiarid environment. Funct Plant Biol 34:683- 691.

10. Barea JM, Palenzuela J, Cornejo P, Sánchez-Castro I, Navarro-Fernández C, LopézGarcía A, Estrada B, Azcón R, Ferrol N, Azcón-Aguilar C (2011) Ecological and functional roles of mycorrhizas in semi-arid ecosystems of Southeast Spain. J Arid Environ 75:1292-1301

11. León-Sánchez L, Nicolás E, Goberna M, Prieto I, Maestre FT, Querejeta JI (2018) Poor plant performance under simulated climate change is linked to mycorrhizal responses in a semi-arid shrubland. J Ecol 106:960-976.

12. León-Sánchez L, Nicolás E, Prieto I, Nortes P, Maestre FT, Querejeta JI (2020) Altered leaf elemental composition with climate change is linked to reductions in photosynthesis, growth and survival in a semi-arid shrubland. J Ecol 108:47-60 
13. Prieto I, Querejeta JI (2020) Simulated climate change decreases nutrient resorption from senescing leaves. Glob Change Biol 26:1795- 1807.

14. Schlaeppi K, Bender SF, Mascher F, Russo G, Patrignani A, Camenzind T, Hempel S, Rillig MC, van der Heijden MGA (2016) High-resolution community profiling of arbuscular mycorrhizal fungi. New Phytol 212:780-791.

15. Krüger M, Krüger C, Walker C, Stockinger H, Schüßler A (2012) Phylogenetic reference data for systematics and phylotaxonomy of arbuscular mycorrhizal fungi from phylum to species level. New Phytol 193: 970-984.

16. Oksanen J, Blanchet FG, Kindt R, Legendre P, Minchin PR, O`Hara RB, Simpson GL, Solymos P, Stevens MHH, Wagner HH (2016) Vegan: Community ecology package. R Package Version 2.4-1 (pp Page).

17. De Caceres M, Legendre P (2009) Associations between species and groups of sites: indices and statistical inference. Ecology 90: 3566e 3574.

18. R Core Team (2019) R: a language and environment for statistical computing. Vienna: R Foundation for Statistical Computing

19. Fuchslueger L, Bahn M, Fritz K, Hasibeder R, Richter A (2014) Experimental drought reduces the transfer of recently fixed plant carbon to soil microbes and alters the bacterial community composition in a mountain meadow. New Phytol 201:663 916-927

20. Karlowsky S, Augusti A, Ingrisch J, Hasibeder R, Lange M, Lavorel S, Bahn M, Gleixner G (2018) Land use in mountain grasslands alters drought response and recovery of carbon allocation and plant-microbial interactions. J Ecol 106:1230-1243

21. Bever JD, Richardson SC, Lawrence BM, Holmes J, Watson M (2009) Preferential allocation to beneficial symbiont with spatial structure maintains mycorrhizal mutualism. Ecol Lett 12:13-21.

22. Hart MM, Reader JR (2002) Taxonomic basis for variation in the colonization strategy of arbuscular mycorrhizal fungi. New Phytol 153:335-344

23. Treseder KK, Allen EB, Egerton-Warburton LM, Hart MM, Klironomos JN, Maherali H, Tedersoo L (2018) Arbuscular mycorrhizal fungi as mediators of ecosystem responses to nitrogen deposition: a trait-based predictive framework. J Ecol 106:480-9.

24. Yang H, Zhang Q, Koide RT, Hoeksema JD, Tang J, Bian X, Hu S, Chen X (2017) Taxonomic resolution is a determinant of biodiversity effects in arbuscular mycorrhizal fungal communities. J Ecol 105:219-228. 

Fig. 1. Mean relative abundance of AMF families in rhizosphere soil under the different climate treatments four years after experiment establishment. Climate treatments are Control, Warming (W), Rainfall Reduction (RR), and Warming plus Rainfall Reduction $(\mathrm{W}+\mathrm{RR})$.

Fig. 2. Sequences abundance for each AMF family found in the rhizospheric soil under the different climate treatments four years after experiment establishment. Climate treatments are Control, Warming (W), Rainfall Reduction (RR), and Warming plus Rainfall Reduction (W+RR). 
Table 1. Mean OTU richness and Shannon-Wiener diversity index for the AMF community (total, 109 OTUs) and the AMF families in soil samples under control, rainfall reduction (RR), warming (W) and warming + rainfall reduction $(\mathrm{W}+\mathrm{RR})$ treatments. Data represent Mean and standard deviation (SD) for each treatment. Values in the same column followed by the same letter are not significantly different according to ANOVAs and LSD post hoc tests $(P<0.05)$.

\begin{tabular}{|c|c|c|c|c|}
\hline & \multicolumn{2}{|c|}{ Richness } & \multicolumn{2}{|c|}{ Shannon-Wiener } \\
\hline AMF OTUs & Mean & SD & Mean & SD \\
\hline Control & $28.19 b$ & 10.56 & $2.26 a$ & 0.63 \\
\hline $\mathrm{RR}$ & $23.75 a b$ & 15.40 & $1.94 a$ & 0.84 \\
\hline W & $16.10 a$ & 10.90 & $1.78 a$ & 0.73 \\
\hline$W+R R$ & 26.18ab & 12.97 & $2.18 a$ & 0.51 \\
\hline \multicolumn{5}{|l|}{ AMF families } \\
\hline Control & $3.25 b$ & 0.77 & $0.31 a$ & 0.30 \\
\hline $\mathrm{RR}$ & $2.37 a$ & 1.19 & $0.22 a$ & 0.15 \\
\hline W & $2.30 a$ & 0.67 & $0.33 a$ & 0.33 \\
\hline$W+R R$ & $2.45 a$ & 0.93 & $0.16 a$ & 0.18 \\
\hline
\end{tabular}


Figures

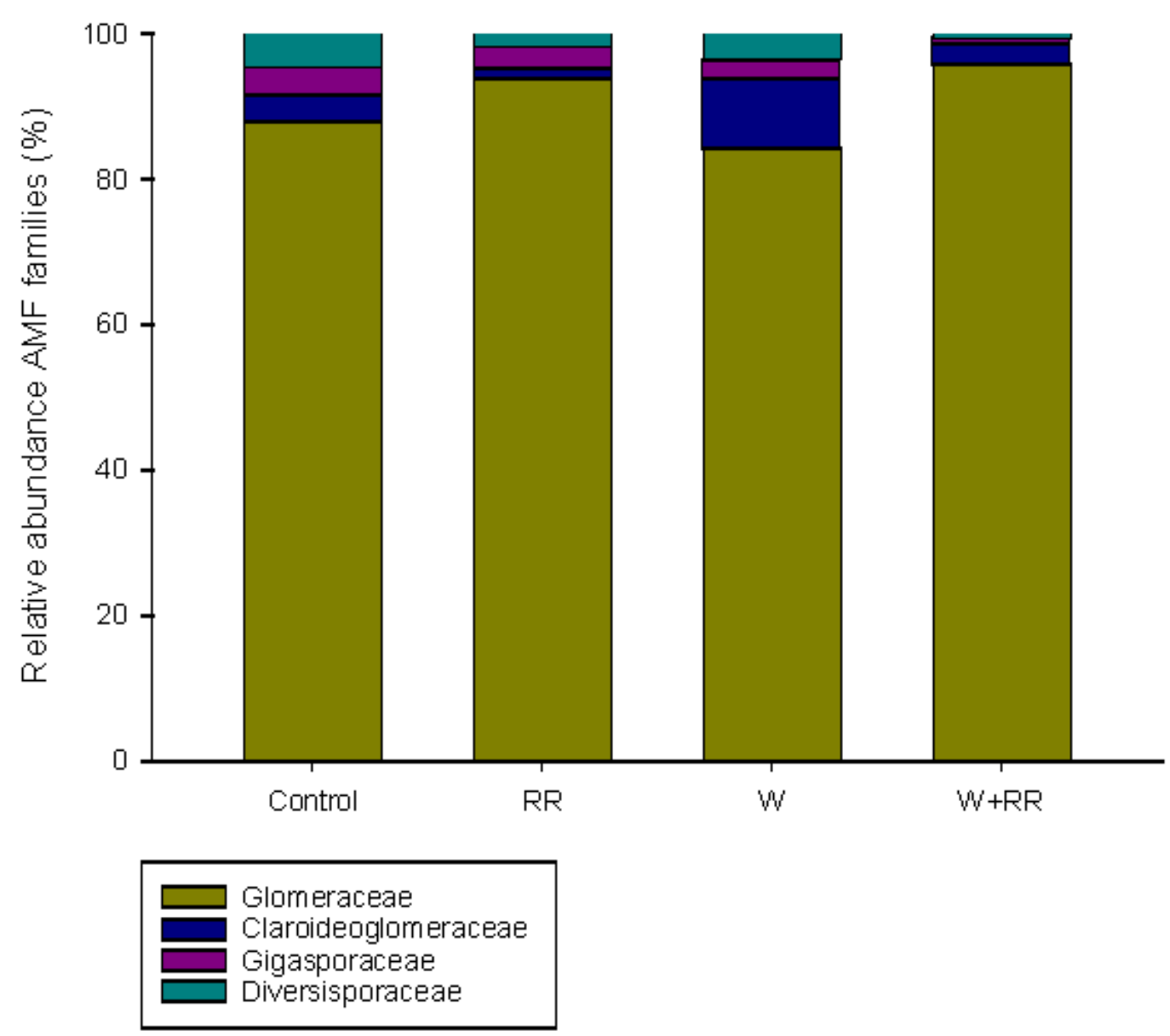

\section{Figure 1}

Mean relative abundance of AMF families in rhizosphere soil under the different climate treatments four years after experiment establishment. Climate treatments are Control, Warming (W), Rainfall Reduction (RR), and Warming plus Rainfall Reduction (W+RR). 

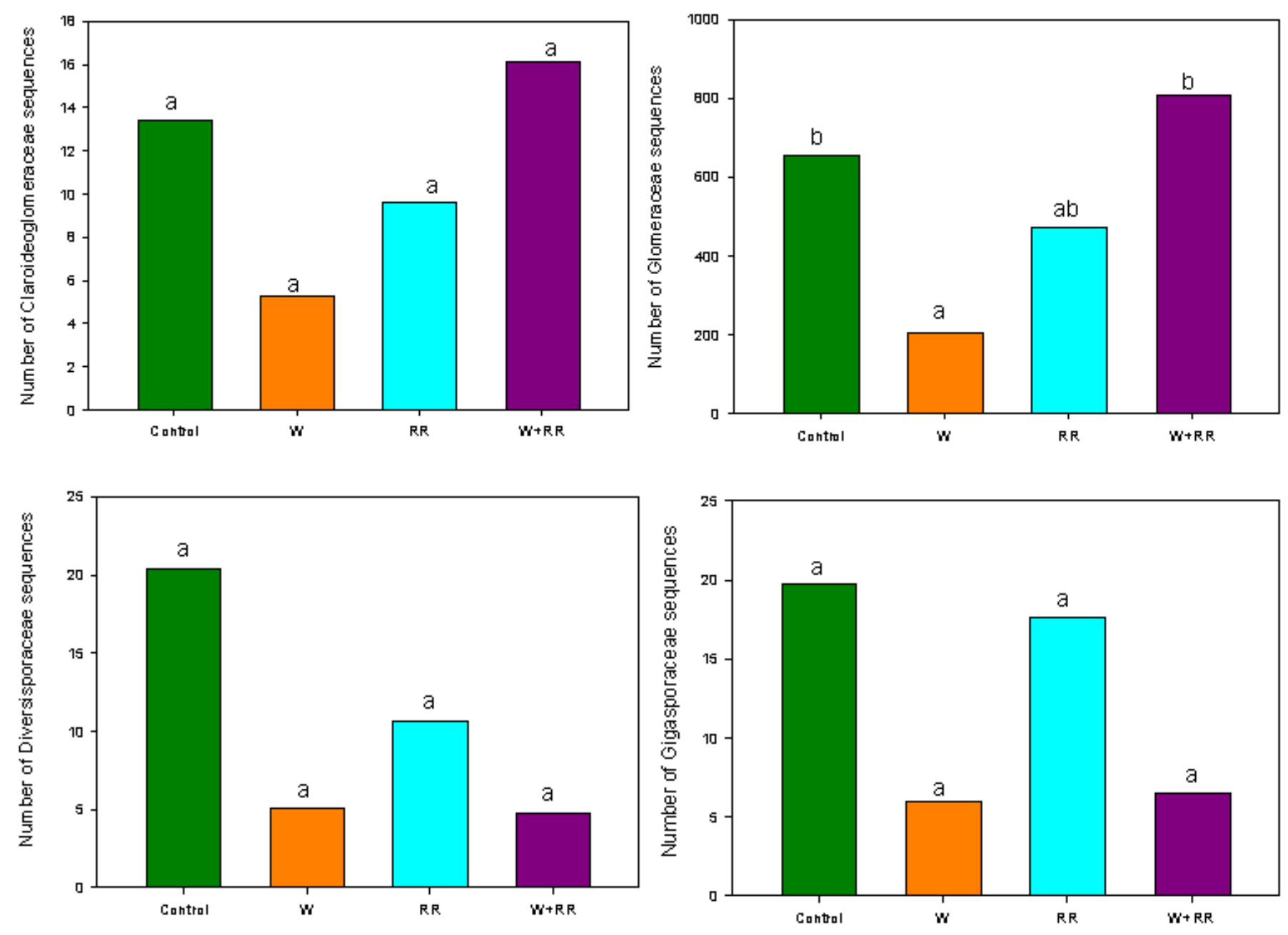

Figure 2

Sequences abundance for each AMF family found in the rhizospheric soil under the different climate treatments four years after experiment establishment. Climate treatments are Control, Warming (W), Rainfall Reduction (RR), and Warming plus Rainfall Reduction (W+RR).

\section{Supplementary Files}

This is a list of supplementary files associated with this preprint. Click to download.

- Supplementarymaterial.docx 